Ss. Ss given the reverse pattern of biasing information (antidriver and provictim) showed lower agreement with antivictim inferences than control Ss but were not differentiated from controls on antidriver inferences. Statements involving observable facts seemed remarkably impervious to subjective distortion due to biasing information. However, it is quite possible that less intelligent $S$ s and a longer delay between film and questionnaire might have yielded a greater impact of bias upon items of fact. In addition, there may be less opportunity for the operation of bias with laboratory Ss, who view a film in relative detachment, than would be true of emotionally aroused witnesses amidst the chaos of an actual accident. The three experimental groups did not differ significantly in readiness to convict the defendant of reckless driving. These findings generally support the notion that if there is strict adherence to judicial procedures which limit witness testimony to direct observations, the effects of observer bias may be held within tolerable limits.
BRUNING, J. L., \& KINTZ, B. L. Computational handbook of statistics. Glenview, Ill: Scott, Foresman, 1968.

ERLANGER, H. S. Jury research in America: Its past and future. Law \& Society Review, 1970, 4, 345-370.

KLECK, R. E., \& WHEATON, J. Dogmatism and responses to opinion-consistent and opinion-inconsistent information. Journal of Personality \& Social Psychology, 1967. 5, 249-252

LANDY, D., \& ARONSON, $E$. The influence of the character of the criminal and his victim on the decisions of simulated jurors. Journal of Experimental Social Psy chology, 1969, 5, 141-152.

MARSHALL, J. Law and psychology in conflict. Garden City, N.Y: Doubleday, 1966.

ROKEACH, M. The open and closed mind. New York: Basic Books, 1960.

STONE, C. P., \& WECHSLER, D. Wechsler memory scale, Form II. New York: Psychological Corporation, 1948.

STONE. V. A. A primacy effect in decision-making by jurors. Joumal of Communication, 1969, 19, 239-247.

\section{NOTE}

1. The film was produced by Stuart Oskamp, Kent Marquis, and James Marshall for research conducted at the University of Michigan.

\title{
Helping behavior: The cry for help
}

\author{
DOROTHY YAKIMOVICH* and ELI SALTZ \\ Center for the Study of Cognitive Processes \\ Wayne State University Detroit, Mich. 48202
}

If an "injured" workman called out for help, $81 \%$ of the college Ss helped him. If the workman groaned in pain but did not call out, only $29 \%$ helped. The difference was significant and could not be accounted for by differences in judgments of amount of pain felt by the workman in the two conditions.

Several years ago, Kitty Genovese was stabbed to death while 38 "nice," middle-class people silently watched her die (Rosenthal, 1964). The event led to a great deal of interest, among social scientists, in the general problem of the circumstances in which one person will help another who is in distress. Milgram (1970) has shown that "nonhelping" is more common in cities than in small towns, and has attributed this to the "social anonymity" and "stimulus overload" conditions inherent in big city life. Latiné \& Darley (1969) have demonstrated that people in groups are less likely to help others than are people alone, and have suggested the construct of "responsibility diffusion"

* The senior author was an NSF undergraduate participant under the National Science Foundation Undergraduate Research Participation Program, Grant GY 7292. The writers wish to thank Mr. Richard Buttrick for his performances as the man in distress. as a basis for this nonhelping behavior. Summarizing the above factors which inhibit helping behavior, Latiné \& Darley (1970) have hypothesized that the observer from whom help is required must perceive the situation to be a true emergency in order for him to help. If other people are near the person in distress, the observer will be less likely to perceive the situation as absolutely requiring his intervention. Moreover, Latiné and Darley suggest that if the observer can dismiss the situation as noncrucial, the chances are good that he will not help, even if he is the only other person present.

The present study was originally designed to test the Latiné-Darley suggestion that the likelihood of helping behavior will increase as a function of the degree of distress of the victim. No danger accrued to the observer if he helped, since the victim was ostensibly an employee of the University who had injured himself by falling off a ladder while washing windows. (As shall be seen, it now appears that the critical independent variable which determined helping behavior was not degree of distress, but was verbal control by the victim over helping behavior.)

A second aspect of the study was an examination of certain differences in personality and values between observers who helped a person in distress and those who did not.

\section{METHOD}

The Ss in the main experiment were 33 male college students enrolled in introductory psychology at Wayne State University during the summer of 1970. All Ss participated in the experiment as part of the course requirement. Assignment to conditions was random, with $17 \mathrm{Ss}$ in the no-verbalization condition and 16 in the verbalization condition. An attractive female coed served as the $E$. An additional eight $S s$ were used as judges for the study; these were all graduate students who volunteered to help in the experiment.

The experimental room was located on the second floor of an old building in an isolated corner of the campus. While S knew that other persons were in the building somewhere, the wing in which the experiment was conducted was deserted. Each $\mathbf{S}$ was tested individually. He was told that the purpose of the experiment was to investigate the values of college students, and was asked to complete a "social values questionnaire," which, S was told, constituted the entire experiment. This questionnaire measured the personality and value dimensions which were later related to helping behavior.

When S started the questionnaire, $E$ indicated that she was going to the next room so that $S$ could work undisturbed. The $S$ could be observed through a one-way mirror. When $S$ began the last page of the questionnaire, $\mathrm{E}$ signaled a confederate to enact the emergency scene.

The confederate was dressed as a workman and was washing the first-floor windows beneath the open window of the experimental room. At E's signal, the confederate knocked over his ladder and pail, screamed, and lay down on the pavement, clutching his ankle. (The $S$ was seated away from the window; thus $S$ was never in a position where he could observe the actual "fall.") The no-verbalization condition was assumed, a priori, to be the low emergency situation; here the confederate continued to moan and clutch his foot, occasionally cursing softly, but never actually called for help. The verbalization condition (assumed to be high-emergency) was identical to the no-verbalization, with 
the exception that the confederate occasionally emitted a cry for help. In neither condition did the confederate look up at the window toward $S$ or indicate awareness that the $S$ might be watching.

The eight graduate student judges were shown the two conditions and were asked to judge in which of the two the confederate appeared to be in greater pain and distress. Four of the judges were shown the verbalization condition first, and the other four were shown the no-verbalization condition first.

The personality and value measures were: (1) the New Left Scale (Christie et al, 1969), which was shortened to contain only the 28 items which correlated .44 or better with total score; (2) Wrightsman's (1964) scales for "trustworthiness," "independence," and "altruism"; (3) a version of Rotter's (1966) scale of internal-external control, with only the 13 items whose correlations with total score were .24 or better being used; (4) a general-activity scale designed by the authors (this was a list of 75 activities ranging from talking on the telephone to flying airplanes; $S$ indicated if he participated in each activity often, seldom, or never).

\section{RESULTS}

All Ss jumped up and went to the window at the sound of the "accident." The criteria for helping behavior were very liberal. An S was scored as having helped if he called out to the confederate to ask if he needed assistance, if he ran down the stairs to the confederate, or if he went next door for E's aid. Nonhelping consisted of simply staring out the window at the victim, then returning to complete the questionnaire. Only one $S$ was questioned by $\mathrm{E}$ as to why he had not helped. He indicated that he had not wanted to "get involved."

The independent variable had a large and significant effect on the likelihood of evoking helping behavior. In the verbalization condition, $81 \%$ (13 of 16) Ss helped the confederate. In the no-verbalization condition, only $29 \%$ (5 of 17) Ss helped. A chi-square test corrected for continuity showed this difference to be significant at $\mathrm{p}<.01\left(\mathrm{x}^{2}=6.9, \mathrm{df}=1\right)$.
Turning to the ratings by the graduate student judges, it should first be noted that all of these found the confederate's performance extremely convincing and that he appeared to be in great pain. The illusion of a fall was so great that one judge asked if the confederate had been trained to fall without injuring himself. Three of the judges considered the no-verbal condition to give the impression of greater pain; five felt there was no difference between conditions. Order of enactment appeared to be unrelated to judgments. Thus, the greater amount of aid in the verbalization condition cannot be attributed to the Ss' interpreting the confederates as being in greater distress or pain than in the no-verbalization condition.

Turning to the personality measures, none of these came close to being significantly related to helping behavior. Contrary to the writers' prior assumptions, the more liberal Ss on the New Left scale were slightly less likely to help than were the more conservative Ss.

While the experimental manipulation had a sizable effect on the number of college Ss who displayed helping behavior, this effect was not related to judgments concerning the degree of emergency involved in the experimental conditions. Then why were more Ss willing to help in the verbalization condition than in the no-verbalization condition? While no systematic inquiries were made on this issue, several of the graduate student judges spontaneously made the same remark. They indicated that they, personally, would have helped in the verbalization condition because the confederate cried out for help.

It should be recalled that in the present study, simply calling out and asking the confederate if he needed help was considered helping behavior. In the no-verbalization condition, $71 \%$ of the college student Ss, liberals and conservatives alike, did not do even this much upon seeing a man writhing in pain below them in the alley. However, if the confederate simply groaned "help" several times, this was enough to reduce the number of nonhelpers to $19 \%$ of the $S$ s in the verbalization condition. These college student Ss were, apparently, unwilling to help except when under conditions of external verbal control.

None of the personality variables or measures of social values examined in the present study were related to helping behavior. This lack of relationship is consistent with the results of previous studies. Darley \& Latiné (1968) measured $\mathrm{Machi}$ avellianism, anomie, authoritarianism, need for approval, and social responsibility in Ss who helped and those who did not help, but no significant differences were found. Similarly, Korte (1969) found no significant effects when he related helping behavior to deference, autonomy, and submissiveness. At present, situational variables appear to be more crucial than personality variables in determining helping behavior.

\section{REFERENCES}

CHRISTIE, R., FRIEDMAN, L., \& ROSS, A. The new left and its ideology. In J.P. Robinson and P. R. Shaver (Eds.) Measures of social psychological attitudes. Ann Arbor: Survey Research Center, 1969

DARLEY, J. M. \& LATINÉ, B. Bystander in tervention in emergencies: Diffusion of responsibility. Journal of Personality \& Social Psychology, 1968, 8, 37 7-383.

KORTE, C. Group effects of help-giving in an emergency. Proceedings of the $77 \mathrm{th}$ Annual Convention of the American Psychological Association, 1969, 4 383-384.

LATINE, B., \& DARLEY, J. M. Bystander apathy. American Scientist, 1969, 57, 2, 244-268.

LATINE. B., \& DARLEY, J. M. Socia determinants of bystander intervention in emergencies. In J. Macaulay and $L$. Berkowitz (Eds.). Altruism and helping behovior. New York: Academic Press, 1970 .

MILGRAM, S. The experience of living in cities. Science, 1970, 167, 3924 . 1461-1468.

ROSENTHAL, A. M. Thirty-eight witnesses. New York: McGraw-Hill, 1964.

ROTTER, J. Generalized expectancies for internal versus extermal control of reinforcement. Psychological Monographs, 1966, 80, Whole No.609.

WRIGHTSMAN, L. Measurement of philosophies of human nature. Psychological Reports, 1964, 14, 743-751. 